dating the growing number of suitably qualified biomedical researchers within a flat budget will remain its toughest problem.

The hit-list of cuts contained in the Contract with America would limit growth in the \$3-billion budget of the National Science Foundation (NSF) to 1 per cent less than inflation. Whatever happens to this list, the Republicans can be relied upon to prevent a repeat of last year's 14 per cent increase in NSF's budget, and to reverse the agency's recent drift away from basic research towards school education and applied research.

Fiscal conservatives are also likely to attack the amount of money that research universities spend on research overheads. What is not clear is how large such cuts will be, or how much mud will stick when Congress holds hearings to 'prove' that universities are wasting public money.

The Department of Defense is the only agency that Republicans want to enlarge. But defence hawks will continue to accuse it of wasting money on university and other research unrelated to battle-readiness. A proposal to bring a halt to such research made recently by Senators John McCain (Republican, Arizona) and John Warner (Republican, Virginia) - may come to nothing, but the point they have sought to make will resonate in the new Congress.

The Department of Energy will probably be the favourite whipping boy of the new Congress. The department's political vulnerability is illustrated by the fact that Clinton chose it as the target for almost half of his own modest package of cuts. But his failure to specify exactly where the cuts would be made again serves as a reminder of the difficulties that Congress will face in the coming year in turning cost-cutting rhetoric into action.

One reason is that the US Constitution, which was drawn up by Virginian landowners, was designed to provide cautious, or even weak, government. Its intricate system of checks and balances - for example, the ability of senators from even small states to obstruct business in the upper house to ensure that their views are heard - rules out drastic changes such as those pursued by Mrs Margaret (now Lady) Thatcher after 1979 during her spell as UK prime minister.

So observers in Washington do not expect a revolution in the new year. Instead, they predict progressive tightening of the austere fiscal environment that has kept spending on science and technology more or less static since 1987, the year when four decades of growth came to an end.

Such a situation would leave the Republican Congress and the Democratic administration on familiar ground, blaming each other for the Congress's failure to deliver its promises to reduce taxes, enlarge the military, shrink government and balance the budget. Such 'gridlock as usual' will not impress the public, but it may be the best that science can hope for during 1995.

Colin Macilwain

\title{
Japan aiming to fund centres of 'excellence' in universities
}

Tokyo. Japan made a series of small but important moves towards reforming its public research system in 1994, to encourage the creation of centres of excellence in universities and government research institutes. The reform process, which will continue in 1995 , is likely to have far-reaching effects on the development of science and technology in Japan.

Japan's 98 national universities come under the central control of the Ministry of Education, Science and Culture, which disperses most university funds in a bureau-
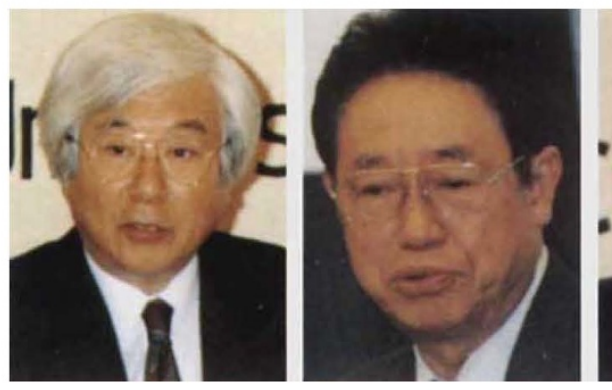

A 'gang of four' university reformers? Yoshikawa (Tokyo University), Esaki (Tsukuba), Oda (formerly of ISAS) and Arima (RIKEN).

cratic, piecemeal fashion without regard for performance. A similar situation prevails in most national research institutes belonging to the education and other ministries. Under such a system, there is little incentive for institutions to excell. But moves for reform are underway.

The reform process began to take root last year with the publication of an external review of the Institute of Space and Astronautical Science - a world leader in $\mathrm{X}$-ray and solar astronomy — carried out by leading scientists and experts from Japan and overseas. This review, initiated by Minoru Oda, a former director general of the institution, followed the first attempt to carry out such reviews in Japan, the previous year, by the physics department of Tokyo University and the Institute of Physical and Chemical Research (see Nature 365, 97; 1993).

In June, the Ministry of International Trade and Industry (MITI) announced plans to assess its 16 research institutes - but the reviews have yet to begin, because of resistance from the research institutes. At the end of last year, another external review, of the new graduate school of mathematical sciences at Tokyo University, was released.

The reformers responsible for establishing these reviews - such as Akito Arima, president of RIKEN and former president of Tokyo University - deny that they will directly influence government decisions on funding. But these generally favourable assessments of some of Japan's leading research institutions should nonetheless help them to attract extra funds.
A new budget to promote centres of excellence was requested in August by the education ministry. This represents a major shift from the traditional practice of spreading money as evenly as possible among Japan's universities.

If the Diet (parliament) approves the budget request this spring, university-related institutes stand to gain an extra $¥ 3$ billion (US\$30 million) annually, while a few small research groups would also each receive grants worth several hundred mil-

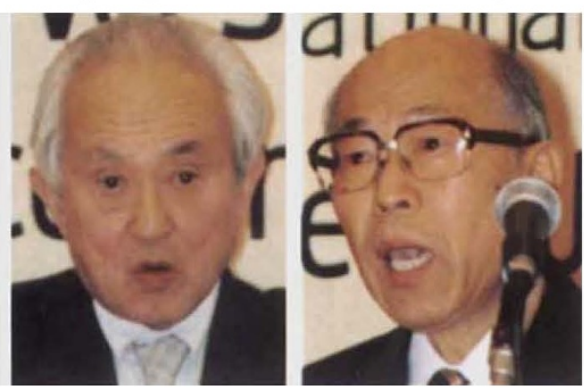

The external reviews have all criticized the lack of foreign staff in Japan's leading research institutions. Robert Geller, from Tokyo University's faculty of science, is one of the few foreign scientists with tenure in Japan's universities. He has already spoken out about the problem (see Nature 372, 721 ; 1994), but considers that major improvements are unlikely because most Japanese universities recruit staff internally.

Until such problems are tackled, Japan's prospects for opening up its universities will remain poor. Indeed, the Ministry of Education, Science and Culture seems to be moving backwards. It is recently reported to have issued a directive encouraging universities to terminate the contracts of senior foreign faculty (over 45) to save money on the higher salaries they command.

In May, Tsukuba University created the Tsukuba Advanced Research Alliance (TARA) to encourage cooperation between its faculty and researchers in industry and government research institutes in Tsukuba science city (Nature 369, 268; 1993). TARA faces many bureaucratic obstacles, but Leo Esaki - president of Tsukuba University and the 1973 Nobel prizewinner in physics _- is determined that it should succeed; he is supported by senior officials in the education ministry.

Similarly, Hiroyuki Yoshikawa, president of Tokyo University, has taken a step towards providing the university, with a greater say in its own financial affairs by setting up a 'presidential fund' (see Nature 372, 394; 1994) lion yen (see Nature 371, 188; 1994). 